
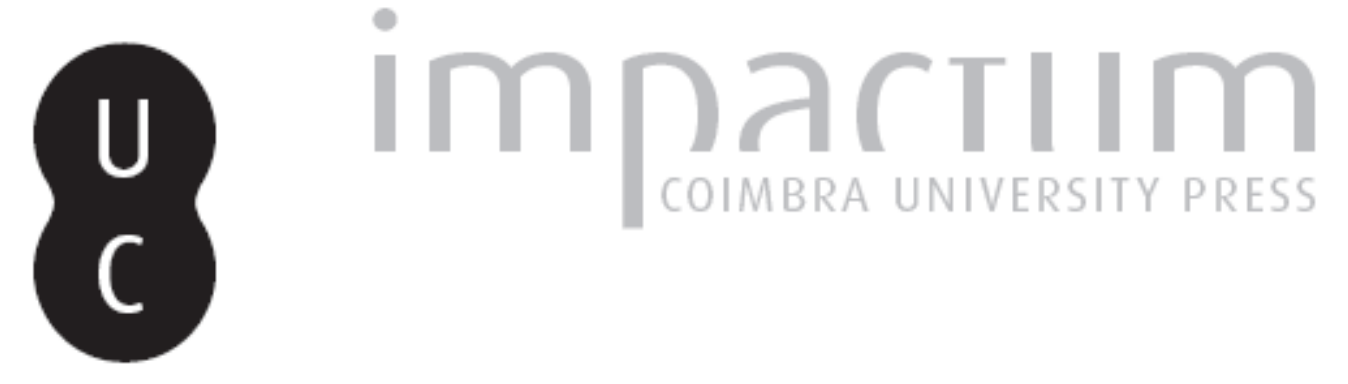

Tempo de passagem: os governos provisórios no contexto da adesão de Portugal à CEE (1974-76)

Autor(es): Cunha, Alice

Publicado por: Centro de História da Sociedade e da Cultura

URL persistente:

URI:http://hdl.handle.net/10316.2/39399

DOI:

DOI:http://dx.doi.org/10.14195/2182-844X_13_17

Accessed : $\quad$ 26-Apr-2023 11:06:28

A navegação consulta e descarregamento dos títulos inseridos nas Bibliotecas Digitais UC Digitalis, UC Pombalina e UC Impactum, pressupõem a aceitação plena e sem reservas dos Termos e Condições de Uso destas Bibliotecas Digitais, disponíveis em https://digitalis.uc.pt/pt-pt/termos.

Conforme exposto nos referidos Termos e Condições de Uso, o descarregamento de títulos de acesso restrito requer uma licença válida de autorização devendo o utilizador aceder ao(s) documento(s) a partir de um endereço de IP da instituição detentora da supramencionada licença.

Ao utilizador é apenas permitido o descarregamento para uso pessoal, pelo que o emprego do(s) título(s) descarregado(s) para outro fim, designadamente comercial, carece de autorização do respetivo autor ou editor da obra.

Na medida em que todas as obras da UC Digitalis se encontram protegidas pelo Código do Direito de Autor e Direitos Conexos e demais legislação aplicável, toda a cópia, parcial ou total, deste documento, nos casos em que é legalmente admitida, deverá conter ou fazer-se acompanhar por este aviso.

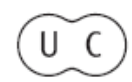



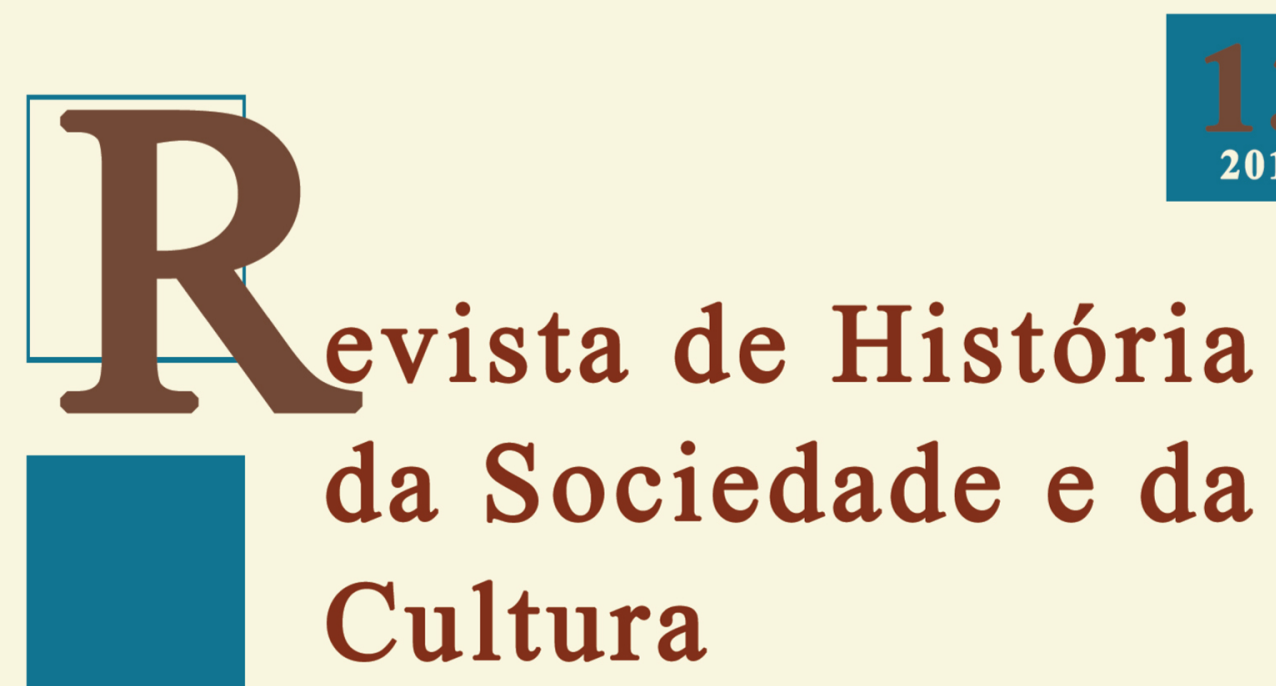

2013

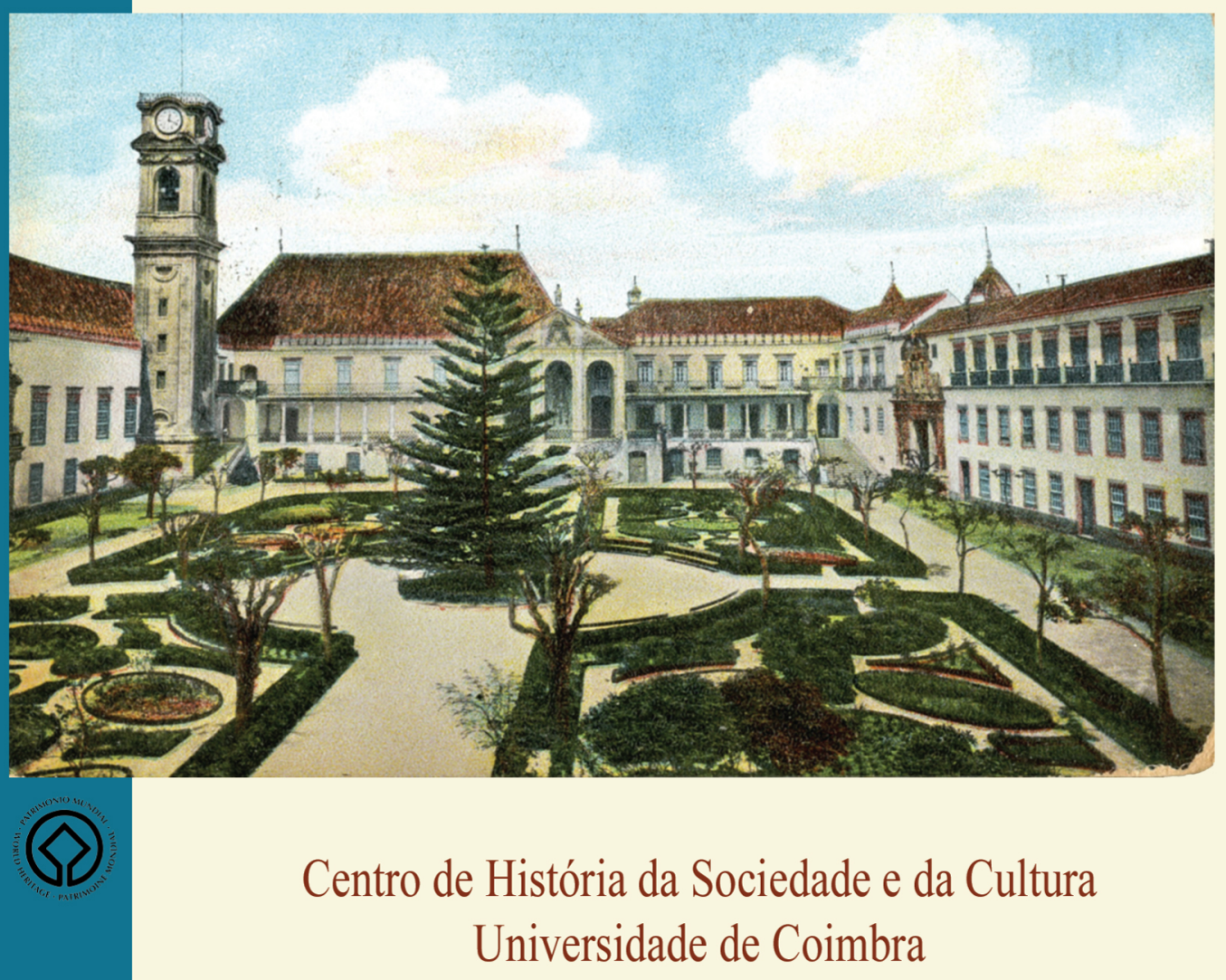

Coimbra 


\title{
Tempo de Passagem: Os Governos Provisórios no Contexto da Adesão de Portugal à CEE (1974-76)
}

\author{
Alice Cunha \\ Instituto de História Contemporânea - Universidade Nova de Lisboa \\ alice_mpbc@hotmail.com \\ Texto recebido em /Text submitted on: 20/05/2013 \\ Texto aprovado em /Text approved on: 10/11/2013
}

\section{Resumo/Abstract:}

A ligação de Portugal com a Comunidade Económica Europeia conheceu diferentes vertentes ao longo do tempo, derivado das vicissitudes da época, das circunstâncias, da política e da economia. Neste aspecto, o 25 de Abril de 1974 estabelece uma fronteira entre um relacionamento estritamente económico e um outro de índole económica mas também política. Este artigo analisará precisamente este espaço de fronteira e os dois anos durante os quais serão evidentes as indecisões dos governos provisórios sobre as fórmulas a adoptar no seu relacionamento com a CEE; e também o apoio, político mas também financeiro, da CEE, condicionado a uma evolução favorável à democracia no país.

The relationship between Portugal and the European Economic Community (EEC) knew different features over time, mainly as a result of political and economical contingencies. To this regard, the 1974's 25 de Abril established a boundary between a strictly economic association and another that would surpass its economic nature and endeavor also to its political nature. This article examines precisely this frontier and the two years during which it will be evident the indecision that the provisional governments would have regarding the formulas to be adopted to what concerns the country's relationship with the EEC; and also the support, political but also financial, given by the EEC, which was restricted upon the favorable development of democracy in the country.

Palavras chave/Keywords:

Comunidade Económica Europeia; Governos provisórios; Política externa; Portugal.

European Economic Community; Provisional governments; Foreign policy; Portugal. 
"Amputado o país do "império», colocava-se-lhe um dos mais complexos e graves desafios estratégicos da sua História: o de se redefinir em termos do seu posicionamento internacional. Problema singularmente mal consciencializado, mal discutido e mal compreendido entre os safanões convulsivos do processo revolucionário ou no seu duro e conflitual rescaldo." 1

\section{Introdução}

Durante anos, no decorrer do Estado Novo, Portugal havia-se acostumado a lidar com a Comunidade Económica Europeia (CEE), maximizando dessa relação os maiores proveitos possíveis e pagando o mínimo dos custos por si aceitáveis. Do lado da CEE, a convivência económica com Portugal também era pacífica. Este relacionamento tranquilo foi abalado a 25 de Abril de 1974 e despoletou uma série de acontecimentos que forçaram tanto o Estado português como os Estados-membros e as instituições comunitárias a redefinirem as suas respectivas posições.

A transição para a democracia portuguesa tem vindo a ser amplamente estudada ${ }^{2}$, incluindo em vertentes específicas, como é o caso da memória, dos partidos políticos, do Conselho da Revolução e do auxílio externo ${ }^{3}$.

1 ROSAS, Fernando - A revolução portuguesa de 1974/5 in MARTINS, Fernando e OLIVEIRA, Pedro Aires (coord.) - As Revoluções Contemporâneas. Lisboa: Colibri, 2005, p. 220.

2 DURÁN MUÑOZ, Rafael - Acciones colectivas y transiciones a la democracia: Espanha y Portugal, 1974-1977. Madrid: Centro de Estudios Avanzados en Ciencias Sociales, 1997; CRUZ, Manuel Braga da - Transições históricas e reformas politicas em Portugal. Lisboa: Bizâncio, 1999; MARTINS, Fernando e OLIVEIRA, P. A. (coord.) - As revoluções contemporâneas. Lisboa: Colibri, 2005; MINOTOS, Marietta (ed.) - The transition to democracy in Spain, Portugal and Greece thirty years after. Athens: Foundation Konstantinos G. Karamanlis, 2006; LEMUS, Encarnación, ROSAS, F. e VARELA, R. (coord.) - O fim das ditaduras ibéricas (1974-1978) = El fin de las dictaduras ibéricas (1974-1978). Lisboa; Sevilha: Edições Pluma-Fundación Pública Andaluza Centro de Estudios Andaluces, 2010.

3 BRITO, Alexandra Barahona de, GONZÁLEZ-ENRÍQUEZ, C. e AGUILAR FERNÁNDEZ, Paloma (coord.) - Política da memória: verdade e justiça na transição para a democracia. Lisboa: ICS, 2004; SABLOSKY, Juliet Antunes - O PS e a transição para a democracia: relações com os partidos socialistas. Lisboa: Notícias, 2000; LISI, Marco-Um 
Por outro lado, a adesão de Portugal à então CEE também começa a ser objecto de estudo de alguns trabalhos académicos mais recentes ${ }^{4}$.

Conjugando ambos, neste artigo pretendemos, numa abordagem histórica, cruzar um pequeno período de tempo do Estado e da História Contemporânea portuguesa com o da própria evolução e essência do projecto de integração europeu, que perfilhava desde o início o princípio da democracia. Assim, o artigo examina de que modo é que os seis governos provisórios pós-25 de Abril se relacionaram com a Europa comunitária, no que diz respeito às suas opções de política externa e de ajuda económica e financeira. Para tal, recorremos não apenas a bibliografia especializada - trabalhos académicos, narrativas pessoais, documentos oficiais -, mas também a fontes arquivísticas, com a utilização de documentação disponível no Arquivo Histórico-Diplomático, e também nos Archives Historiques de la Commission Européenne (Bruxelas) e Historical Archives of the European Union (Florença).

Poder-se-ia considerar que, uma vez findo o Estado Novo, também estaria "ultrapassável o handicap político que não permitia uma total relação com as Comunidades, ou seja, uma relação de aproximação e aprofundamento no sentido da adesão do Estado português como membro de pleno direito

partido revolucionário na transição para a democracia: o PCP entre 1974 e 1976. Lisboa: ISCTE, 2002; REZOLA, Maria Inácia - O Conselho da Revolução e a transição para a democracia em Portugal (1974-1976). Lisboa: Campo da Comunicação, 2006; SÁ, Tiago da Mota Veiga Moreira de - Os Estados Unidos da América e o processo de transição para a democracia em Portugal: o apoio à instauração da democracia (1974-1976). Lisboa: Universidade Lusíada, 2001; FONSECA, Ana Mónica - É preciso regar os Cravos! A Social Democracia Alemã e a transição portuguesa para a democracia (1974-1976). Lisboa: ISCTE, 2011.

4 FERREIRA, Luiz Gongaza - Portugal e as Comunidades Europeias - do 25 de Abril ao pedido de adesão. Lisboa: Vega, 2001; VARIZ, Manuel de Santos - Da adesão de Portugal às Comunidades Europeias (1947-1986). Lisboa: FLUL, 2001; CUNHA, Alice - À descoberta da Europa - a adesão de Portugal às Comunidades Europeias. Lisboa: Ministério dos Negócios Estrangeiros, 2007; CASTRO, Francisco Niny de - O pedido de adesão de Portugal às Comunidades Europeias - aspectos político-diplomáticos. Cascais: Principia, 2010; CHAVES, Miguel de Matos - As negociações de adesão de Portugal à Comunidade Económica Europeia-C.E.E.: 1977/1985. Lisboa: UCP, 2012; CUNHA, Alice - O alargamento ibérico da Comunidade Económica Europeia: a experiência portuguesa. Lisboa: FCSH, 2012. 
na CEE" , mas tal não seria nem um dado adquirido, nem de todo assim tão linear, como demonstraremos ao longo do texto.

\section{Opções de política externa}

O Programa do Movimento das Forças Armadas (MFA) é muito lacónico quanto à política externa, constando apenas que o governo provisório orientar-se-á "pelos princípios da independência nacional e da igualdade entre os Estados, da não ingerência nos assuntos internos dos outros países e da defesa da paz, alargando e diversificando relações internacionais com base na amizade e cooperação", acrescentando que "respeitará os compromissos internacionais decorrentes dos tratados em vigor" ${ }^{\text {. Esta falta }}$ de clareza irá, todavia, ser restringida devido a dois dos princípios que imperam nesse Programa - democratização e descolonização - que, em conjunto, contribuirão para "uma alteração de fundo na orientação externa do Estado português"?.

Como refere Rui Almeida, "a unidade europeia não estava nos horizontes dos autores do golpe de Abril. Quer o programa do MFA, quer os documentos programáticos que se seguiram, apontaram sempre para outras metas e outros destinos, nem sempre condizentes com a adesão às Comunidades Europeias", ao que acrescia o facto de "a liderança militar

5 MENDES, Pedro - A dimensão internacional da transição democrática em Portugal: a influência da Europa. População e Sociedade, 11 (2004) 184.

6 Programa do Movimento das Forças Armadas, ponto 7.

7 TEIXEIRA, Nuno Severiano - Entre a África e a Europa: A Política Externa Portuguesa 1890-2000 in PINTO, António Costa (coord.) - Portugal Contemporâneo. Lisboa: Dom Quixote, 2005, p. 112.

O Programa do MFA foi alterado pelo primeiro Pacto MFA/Partidos, em 1975, no qual apenas é referido que, no que diz respeito a relações externas, os diplomas aprovados pela Assembleia da República têm que ser apreciados e promulgados pelo Conselho da Revolução. Ao Pacto MFA/Partidos seguiu-se o Plano de Acção Política do MFA e do IV Governo Provisório que, à semelhança do anterior, não evoluiu na definição de referências concretas quanto ao futuro da política externa portuguesa. O mesmo acontecendo com o segundo Pacto MFA/Partidos (Plataforma de Acordo Constitucional entre o MFA e os Partidos Políticos), aprovado em 1976.

8 ALMEIDA, Rui Lourenço Amaral de-Portugal e a Europa-Ideias, Factos e Desafios. Lisboa: Edições Sílabo, 2005, p. 269. 
revolucionária [estar] comprometida, em questões de política externa, com uma orientação terceiro-mundista e a maioria dos militares ainda não tinha

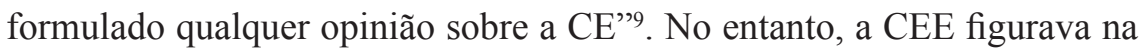
lista de preocupações da Junta de Salvação Nacional, como se comprova no Decreto-Lei n. ${ }^{\circ}$ 203/74 de 15 de Maio, no qual se advoga a "intensificação das relações comerciais e políticas com os países da Comunidade Económica Europeia".

Nos primeiros tempos da recém-designada democracia, sobretudo após o 28 de Setembro, instalou-se uma "luta surda e muda sobre as grandes opções da política externa portuguesa" ${ }^{10}$. Não existia uma verdadeira orientação quanto às opções a tomar, o que contribuiu para uma multiplicação de auto-nomeados centros de decisão e de contacto com o exterior, de entre os quais figuravam a Igreja, partidos, sindicatos, organizações de informação e grupos económicos ${ }^{11}$ que, individualmente, tinham o seu próprio entendimento e agenda ${ }^{12}$ e estabeleciam os seus próprios contactos, o que favoreceu a concorrência entre instituições e indivíduos, sendo que durante 1975 "a desarticulação do sistema de relações externas do País estará consumada", não existindo já aliança inglesa, nem Brasil, nem África ${ }^{13}$.

A questão da orientação da política externa ${ }^{14}$ é pertinente, na medida em que as opções tomadas serão definidoras do relacionamento futuro do Estado português com os outros Estados, europeus e mundiais. Se bem que

9 SABLOSKY, Juliet Antunes - O PS e a Transição para a Democracia: Relações com os Partidos Socialistas. Lisboa: Notícias, 2000, p. 115.

${ }^{10}$ FERREIRA, José Medeiros - Aspectos Internacionais da Revolução Portuguesa. Prospectivas. 2 (1980) 10.

${ }^{11}$ TELO, António José - A Revolução e a Posição de Portugal no Mundo in ROSAS, Fernando (coord.) - Portugal e a Transição para a Democracia (1974-1976). Lisboa: Colibri, 1999, p. 276.

${ }^{12}$ A este respeito, António Telo refere que "os agentes multiplicam-se e quase todos têm projectos e estratégias próprios (...) os projectos e estratégias são muitas vezes bizarros e exóticos, só compreensíveis tendo em conta a mentalidade muito própria e original das personagens envolvidas, que, sem estarem preparados na sua maioria, são arrastados no turbilhão da mudança rápida". TELO, António José - A Revolução..., cit., p. 276.

${ }^{13}$ CASTRO, Armando Antunes e SOUSA, J. F. - Teses sobre uma Estratégia de Relações Externas para Portugal nos Anos 80. Nação e Defesa. 24 (1982) 16.

${ }^{14}$ Sobre a formulação e a implementação das decisões de política externa entre $1974 \mathrm{e}$ 1976, consultar: MOREIRA, Diogo - Transitional Foreign Policy: Actors, Institutions and Norms. Portuguese Journal of Social Science, 4, No. 3 (2005) 123-144. 
não haja uma opção exclusiva, há sempre uma opção dominante que, até então, havia sido o Atlântico e as colónias.

De entre o leque de opções hipoteticamente disponível, figuravam a CEE/espaço europeu ocidental; a adopção de um modelo de isolamento total (=albanização); a inserção no bloco dos Estados do Terceiro Mundo; a efectivação da adesão ao bloco dos países de economia centralizada ${ }^{15}$; e ainda a criação de um espaço económico, que correspondesse aos países de expressão portuguesa. Estas hipóteses eram suportadas por diferentes intervenientes da esfera política, sendo que Vasco Rato aponta três grandes estratégias em torno da política externa:

- o PCP e os seus aliados gonçalvistas defendiam o alinhamento de Portugal com a União Soviética e os demais membros do "bloco socialista", o que se traduziria numa reorientação radical na política externa e de defesa, sendo uma estratégia de reorientação do Ocidente para Leste;

- os "meloantunistas" ou moderados do MFA eram partidários de uma estratégia terceiro-mundista, a qual preconizava a adopção de uma política externa neutral e solidária com o Terceiro Mundo, sem corte de relacionamento com os países europeus, embora sem integração plena na Europa, devido ao subdesenvolvimento económico português;

- após o 25 de Novembro de 1975, a primeira opção é inviabilizada, a segunda enfraquecida, e surge a opção democrática/ocidental, que surge "virtualmente inquestionável"; é apresentada pelos partidos à direita do PCP e pelos sectores militares tradicionalistas, na qual é assegurada que a consolidação da democracia pressupõe a adesão à CEE e a preservação do laço transatlântico ${ }^{16}$.

Na realidade, além da opção europeia, a praticabilidade das restantes opções era reduzida. Como salienta José Cândido de Azevedo, “o problema que se coloca (...) no dealbar da década actual [70] já não é verdadeiramente o de optar ou não pela Europa. Essa opção estava feita"17, sendo classificadas

${ }^{15}$ CUNHA, Paulo de Pitta e - O Desafio da Integração Europeia. Lisboa: Imprensa Nacional-Casa da Moeda, 1980, p. 50-51.

${ }^{16}$ RATO, Vasco - A Revolução de Abril na Política Externa in ALMEIDA, João Marques de e RAMOS, R. (ed.) - Revoluções, Política Externa e Política de Defesa em Portugal: Séc. XIX-XX. Lisboa: Edições Cosmos e Instituto de Defesa Nacional, 2008, p. 209-215.

17 AZEVEDO, J. Cândido de - Portugal, Europa face ao Mercado Comum - Dossier da Adesão de Portugal à CEE. Lisboa: Livraria Bertrand, 1978, p. 28. 
de "totalmente fantasistas as posições dos que (...) defendiam modelos de desenvolvimento auto-sustentado, (...) e advogavam a intensificação das relações económicas com países do Terceiro Mundo e do bloco comunista" ${ }^{18}$. De resto, "as análises não marxistas (...) estavam todas de acordo em que não havia uma alternativa política viável à adesão à CEE" e que "das três opções políticas alternativas - a via independente, a do COMECON e a do Terceiro Mundo -, nenhuma era viável"19. Mesmo assim, a opção europeia não reunia, como observamos, consenso, tendo tanto apoiantes à adesão, como detractores da mesma (ultranacionalistas, comunistas, terceiro-mundistas), e adeptos do regime comercial, na vertente da associação ${ }^{20}$.

Durante esta fase de transição pós-25 de Abril, em relação à política externa podemos delimitar três períodos distintos, nos quais sobressaem diferentes prioridades:

- a descolonização, até 25 de Novembro de 1975, na qual é contemplado o alargamento das relações diplomáticas, nomeadamente aos países do Leste, à África, Ásia e mundo árabe;

- a definição do tipo de regime a estabelecer no país, procurando apoios no estrangeiro; aproximação à CEE, com vista à angariação de financiamento para o Estado e o aprofundamento das relações comerciais;

- a Europa que, a partir do final de 1975, começa a reforçar a sua posição no contexto da definição da política externa portuguesa ${ }^{21}$.

Será, deste modo, apenas em 1976, quase dois anos após o 25 de Abril, que haverá um "corte com as políticas africanas, terceiro-mundistas, gonçalvistas e europeio-comercialistas que ainda em 1975 se digladiavam nas mais altas instâncias do poder político"22.

${ }^{18}$ LOPES, José Silva - Portugal e a Transição para a Democracia: Que Modelo Económico? in ROSAS, Fernando (coord.) - Portugal e a Transição para a Democracia (1974-1976). Lisboa: Edições Colibri, 1999, p. 176.

${ }^{19}$ LEITÃO, Nicolau Andresen (org.) - 20 Anos de Integração Europeia (1986-2006): O Testemunho Português. Chamusca: Edições Cosmos, 2007, p. 275.

${ }^{20}$ GAMA, Jaime - A Adesão de Portugal às Comunidades Europeias. Política Internacional. 10 (1993) 8.

${ }^{21}$ TELO, António José - A Revolução..., cit., p. 281-308.

${ }^{22}$ FERREIRA, José Medeiros - A Nova Era Europeia - De Genebra a Amesterdão. Lisboa: Editorial Notícias, 1999, p. 37. 


\section{O discurso e a prática: democracia e ajuda financeira}

A situação política portuguesa e as solicitações apresentadas à CEE fizeram com que diversos responsáveis europeus ${ }^{23}$ visitassem Portugal a partir de 1974, sendo as mesmas retribuídas por representantes governamentais portugueses $^{24}$ visitassem Portugal a partir de 1974, sendo as mesmas retribuídas por representantes governamentais portugueses que pretendiam conhecer qual a posição da CEE em relação a Portugal e às suas pretensões.

Menos de um mês após o 25 de Abril, o I Governo Provisório (GP) inicia funções a 16 de Maio de 1974, mas apenas durará dois meses e dois dias, devido à demissão do Primeiro-ministro Adelino da Palma Carlos,

${ }^{23}$ Presidente em exercício do Conselho Van der Stöel, comissários Claude Cheysson e Altiero Spinelli (13-15 de Dezembro de 1974); director-geral das Relações Externas Wellenstein, director Relações Externas Roland de Kergorlay; presidente da Comissão Xavier Ortoli. Archives Historiques de la Commission Européenne (AHCE), BAC 250/1980 n. ${ }^{\circ} 372$, "Relations entre la Communauté et le Portugal", 4 Février 1975.

${ }^{24}$ Ministro da Economia Rui Vilar; Ernesto Melo Antunes e José da Silva Lopes.

A primeira visita oficial dos novos dirigentes políticos à Comissão aconteceu a 26 de Junho de 1974, com o Primeiro-ministro Adelino da Palma Carlos, acompanhado pelo ministro dos Negócios Estrangeiros Mário Soares, que se reuniram com o presidente da Comissão Xavier Ortoli e com o comissário Christopher Soames, com quem falaram sobre a situação política e económica portuguesa e sobre o relacionamento futuro entre Portugal e a CEE. Da parte dos dirigentes da CEE foi dito que a associação não seria a melhor fórmula para o seu relacionamento futuro. AHCE, BAC 250/1980 n. 372 , "Relations entre la Communauté et le Portugal", 4 Février 1975.

A 15 de Novembro de 1974, o ministro da Economia Rui Vilar visita a Comissão, por iniciativa portuguesa, no contexto do desenvolvimento e eventual aprofundamento das relações entre Portugal e a CEE, onde se reuniu com Sir Christopher Soames, o mais longo dos encontros, e também com Claude Cheysson, Xavier Ortoli e Altiero Spinelli. No encontro com o comissário Soames, o ministro explicou a situação portuguesa no que diz respeito aos aspectos económicos e sociais e como resposta obteve o reconhecimento das dificuldades inerentes à descolonização e à democratização, e às dificuldades económicas no contexto da grave situação económica internacional, acrescentando que se a CEE não correspondesse aos anseios portugueses, não seria por falta de vontade, mas devido aos seus próprios problemas (AHCE, BAC 250/1980 n. ${ }^{\circ}$ 248, "Visit by Mr. E. P. Vilar, Minister for Economic Affairs in Portugal"). Na reunião que teve com Spinelli, o ministro apontou os três problemas principais com os quais Portugal se deparava - investimento privado europeu, transferência de tecnologia adaptada à indústria portuguesa, cooperação industrial entre pequenas e médias empresas portuguesas e europeias. Da parte da CEE, Spinelli afirmou que a Comissão estava política e economicamente disposta a ajudar Portugal nas suas pretensões, na medida da sua competência, solicitando para tal dados adicionais, sobretudo a nível de legislação. AHCE, BAC 250/1980 n. ${ }^{\circ} 248$, "Visite de Monsieur Vilar, Ministre Portugais de l'Economie chez M. Spinelli, vendredi 15 novembre 1974”. 
na sequência de manifestações e de greves. No que diz respeito à Europa, no seu Programa de Governo consta a "intensificação das relações comerciais e políticas com os Países da Comunidade Económica Europeia"25, e mesmo em tão curto período de tempo de vigência deste governo, houve a possibilidade, na terceira reunião do Comité Misto ${ }^{26} \mathrm{CEE}-$ Portugal, realizada em Bruxelas, a 27 de Junho de 1974, para o governo português exprimir a intenção de recorrer à cláusula evolutiva ${ }^{27}$, demonstrando assim interesse na "consolidação e intensificação das relações existentes" com a $\mathrm{CEE}^{28}$, e o seu ministro dos Negócios Estrangeiros, Mário Soares, anunciar que "a política externa de Portugal vai mudar $180^{\circ}$ graus" 29 . Estas palavras podem ser lidas no contexto de um governo ao qual faltava uma definição política clara e no qual o Ministro "encontrava margem suficiente para ir pondo em prática as suas ideias relativamente à política externa portuguesa (...), mas com alguma cautela, atendendo à delicadeza política do momento"30.

De resto, em conferência de imprensa, realizada no Palácio das Necessidades, a 13 de Setembro de 1974, o então Ministro faz um ponto de situação sobre os aspectos mais importantes da política externa do país, na qual inclui o Mercado Comum, designação habitual à época para designar a CEE. A esse respeito refere que o governo fez uma primeira abordagem, sob a forma de encontros bilaterais e multilaterais, à CEE, mas que à data a melhor opção, validada por todas as partes, seria a de melhorar e ampliar

${ }^{25}$ PORTUGAL - Governo Provisório: Homens e Programa. Lisboa: Ministério da Comunicação Social, 1974, p. 42.

${ }^{26}$ Entidade encarregada de gerir o acordo de comércio livre de 1972.

${ }^{27}$ Manifestou também esperança de que a CEE ajudasse rapidamente a economia portuguesa; sublinhando igualmente o vínculo do país para com o princípio democrático e para com os objectivos fundamentais da CEE. AHCE, BAC 250/1980 n. ${ }^{\circ} 372$, "Relations entre la Communauté et le Portugal", 4 Février 1975. Do lado da CEE, notou-se com agrado a evolução da política portuguesa em direcção à democracia e demonstrou-se satisfação pela possibilidade de encetar relações mais estreitas com Portugal.

${ }^{28}$ ALMEIDA, Rui Lourenço Amaral de - Portugal e a Europa ..., cit., p. 275.

${ }^{29}$ SOARES, Mário - Portugal e a Transição para a Democracia: Um Testemunho Pessoal in ROSAS, Fernando (coord.) - Portugal e a Transição para a Democracia (1974-1976). Lisboa: Colibri, 1999, p. 326.

${ }^{30}$ SEBASTIÃO, Dina Sofia Neves - Mário Soares e a Europa: Pensamento e Acção. Coimbra: Faculdade de Letras da Universidade de Coimbra, 2010, p. 56. 
os acordos comerciais existentes, considerando todavia que não importava apenas fortalecer laços a nível económico, mas também ao nível político ${ }^{31}$.

Curiosamente, adiante, respondendo, a um jornalista belga que o questionou sobre os planos portugueses para a adesão ao Mercado Comum, disse que o país "não deveria, desde logo, pretender um estatuto de associado e, menos ainda, um acordo de integração, porque o estado de desenvolvimento da nossa economia não o permite" e acrescenta que a adesão não era assim possível na altura, e que a liberdade de circulação de capitais, pessoas e bens seria desastrosa para a economia portuguesa de então ${ }^{32}$.

Mesmo assim, e vivendo tempos conturbados, Portugal começou a renegociar alguns termos dos acordos de $1972^{33}$, ao abrigo da cláusula evolutiva, que eram, na realidade, mais benéficos para a CEE do que para Portugal, dado que oficializaram uma relação já existente entre ambos e que era mais favorável à CEE.

Logo no dia seguinte à demissão de Adelino da Palma Carlos, inicia funções Vasco Gonçalves com o II GP em cuja formação, ao contrário do carácter pluripartidário do I GP, prevaleceu o entendimento entre os militares do MFA e o PCP, iniciando-se então uma viragem à esquerda. Mas este GP também será de curta duração, sendo que a 25 de Novembro, já tomará posse o III GP, que não só assume formalmente no respectivo programa a vontade de aprofundamento das relações de cooperação a vários níveis ${ }^{34}$, como irá apresentar propostas para modificar determinadas cláusulas dos acordos comerciais CEE-Portugal, e para alargar a cooperação a outros domínios.

Na reunião do Comité Misto, realizada em Lisboa, a 25 e 26 de Novembro de 1974, o III Governo Provisório reitera a sua intenção de que certas

${ }^{31}$ SOARES, Mário - Portugal's new foreign policy. Lisbon: Ministry of Foreign Affairs, 1974, p. 27-28.

32 SOARES, Mário - Portugal's..., cit., p. 37-38.

${ }^{33}$ Acerca da abertura das negociações para a revisão dos acordos de 1972, negociações propriamente ditas e consequentes Protocolo Adicional e Protocolo Financeiro consultar: AHCE, BAC 48/1984 n. ${ }^{\circ}$ 563/3, 4 e 5; AHCE, BAC 48/1984 n. ${ }^{\circ}$ 564/1, 2, 3, 4 e 5.

${ }^{34}$ SILVA, António Martins da - Portugal e a Europa - Distanciamento e Reencontro A Ideia de Europa e a Integração Europeia: Ecos, Reaç̧ões e Posicionamentos (1830-2005). Viseu: Palimage Editores, 2005, p. 409. 
cláusulas dos acordos sejam modificadas ${ }^{35}$, mas será apenas a 20 de Janeiro de 1976, que o Conselho de Ministros da CEE autorizou a Comissão a encetar negociações com Portugal, sendo que só depois de quase seis meses de negociações, é que as delegações portuguesa e comunitária chegariam a acordo, a 9 de Junho de $1976^{36}$, sobre o conteúdo do Protocolo Adicional ao Acordo de 1972 e sobre um Protocolo Financeiro ${ }^{37}$.

Este será, porém, um empreendimento fugaz, pois uma remodelação governamental conduzirá, quatro meses mais tarde, ao IV GP, que terá, em relação à Europa, uma posição "delicadamente distante mas reticente" 38 .

De visita a Bona (19 e 20 de Maio de 1975), o ministro dos Negócios Estrangeiros deste GP, Ernesto Melo Antunes, referiu expressamente que,

${ }^{35}$ Havia sido já na terceira reunião do Comité Misto CEE-Portugal, realizada a 27 de Junho de 1974, que o governo português exprimiu a intenção de recorrer à cláusula evolutiva. No entanto, de acordo com as observações da CEE, na reunião de Novembro, a delegação portuguesa limitou-se a apresentar propostas genéricas no âmbito da cooperação financeira, sem ser específica quanto às mesmas, numa altura em que nem sequer se conhecia ainda a orientação de política económica por parte do governo, dado que ainda estava a ser formulado um plano económico para o país. AHCE, BAC 250/1980 n. ${ }^{\circ} 372$, "Relations entre la Communauté et le Portugal", 4 Février 1975.

Previamente, o Conselho, reunido a 12 de Novembro de 1974, havia dado o seu assentimento para que a delegação comunitária no Comité Misto examinasse as pretensões portuguesas e para tal recolhesse todos os elementos necessários, de modo a formular recomendações, para que fossem iniciadas, no tempo e no modo apropriados, negociações. AHCE, BAC 48/1984 n. ${ }^{\circ}$ 563/1, "Communication à la Commission transmise par Sir Christopher Soames, Vice-Président”, 13 Mai 1975.

${ }^{36}$ Como sugeriu Christopher Soames a Francisco Sá Carneiro, seria do interesse de Portugal assegurar um acordo antes das eleições, o que implicaria, por um lado, aceitar cláusulas que não satisfaziam por completo as pretensões portuguesas, sendo que, no fundo, os termos do mandato concedido à Comissão dificilmente seria objecto de revisão e melhoramento por parte dos Estados-membros. AHCE, BAC 250/1980 n. ${ }^{\circ}$ 504, "Record of a call on Sir Christopher Soames by Mr. Sá Carneiro, President of the Portuguese Popular Democratic Party, and Professor Sousa on 27 January 1976”, 28 January 1976.

${ }^{37}$ Com o Protocolo Adicional foram melhorados certos aspectos comerciais, com regimes mais favoráveis para determinadas exportações portuguesas e com maior protecção para a indústria, complementando e expandindo os acordos de 1972 ao nível da agricultura, comércio e indústria, e abrangendo novos sectores através de cooperação a nível do emprego e da segurança social e também da cooperação financeira, industrial e tecnológica. No que diz respeito à cooperação financeira, o Protocolo Financeiro previa uma ajuda de emergência de 180 milhões UC.

${ }^{38}$ MARTINS, Maria Helena Gomes - Portugal e a Aproximação à Europa - Do Acordo de 1972 ao Pedido de Adesão, Lisboa: Faculdade de Ciências Sociais e Humanas, 2006, p. 106. 
na altura, uma adesão de Portugal à CEE estava excluída, devido nomeadamente ao fraco desenvolvimento económico ${ }^{39}$. Mas subjacente a tal declaração, estava uma inflexão governativa à esquerda, que havia culminado com o 11 de Março de 1975 e com as consequentes nacionalizações. Justamente, "a radicalização do processo revolucionário irá dificultar o estreitamento de relações com a Europa", não apenas pela rigidez da CEE em apenas apoiar um regime democrático, mas muito também porque os governos provisórios, sobretudo o IV e o V, "não estão empenhados neste reforço, tendo sido rejeitada qualquer hipótese de associação à Comunidade e assumido expressamente o relacionamento privilegiado com os países do Terceiro Mundo" ${ }^{40}$, embora não se notasse especificamente em Melo Antunes "falta de interesse pela CEE, nem reacções negativas à aproximação à Europa. Melo Antunes é claramente pró-europeu"41.

Assistiu-se, assim, na primavera de 1975, a um agravamento da situação política, sendo apenas a 25 de Novembro desse ano que um golpe militar travará os avanços da esquerda. A CEE mantinha-se atenta ao desenrolar dos acontecimentos e inquietava-se com a sucessão dos governos provisórios e, sobretudo, com a tendência para a instauração de um regime de esquerda, vislumbrando a possibilidade de o país rumar em direcção ao comunismo ${ }^{42}$, pelo que respondia com muita cautela às solicitações portuguesas.

Ainda assim, expectante ${ }^{43}$ em relação ao rumo que Portugal iria tomar, os encontros sucediam-se, tendo sido, por esta altura, recebido o comissário

${ }^{39} \mathrm{AHCE}, \mathrm{BAC} 48 / 1984$ n. ${ }^{\circ}$ 563/1, AHCE, BAC 48/1984 n. ${ }^{\circ}$ 563/1, "Note à l'Attention du Président Ortoli sous Couvert du Vice-Président Sir Christopher Soames - Visite de M. Melo Antunes, ministre des Affaires Étrangères”, 23 Mai 1975.

${ }^{40}$ SILVA, António Martins da - Portugal e a Europa ..., cit., p. 410.

${ }^{41}$ BRITO, José Maria Brandão de, ROLLO, M. F. e AMARAL, J. F. (ed.) - Portugal e a Europa..., cit., p. 204.

42 A presença dos comunistas nos governos provisórios nunca foi bem encarada por nenhum Estado-membro. A RFA, sobretudo, depois do 25 Abril, ajudou na construir a oposição aos radicais e aos comunistas, sendo, nesse sentido, responsável pelo regime no poder desde final de 1975. Sobre o papel da RFA na transição para a democracia portuguesa, consultar: FONSECA, Ana Mónica - The Federal Republic of Germany and the Portuguese Transition to Democracy (1974-1976). Journal of European Integration History. 15, No. 1 (2009) 35-56.

${ }^{43}$ Mesmo neste clima de incerteza, a 5 de Maio de 1975, o Conselho irá pedir à Comissão que elabore um relatório sobre as relações entre Portugal e a CEE para, com base nesse documento, encetar discussões sobre o seu relacionamento futuro. AHCE, BAC 48/1984 
Christopher Soames ${ }^{44}$, constando na agenda desta visita os acordos CEE-Portugal, as relações entre Portugal e a CEE, a evolução política portuguesa e a sua política externa.

Quadro I - Os governos provisórios e o seu relacionamento com a CEE

\begin{tabular}{|c|c|}
\hline Governo Provisório & Relação com a CEE (avanços e recuos) \\
\hline $\begin{array}{c}\text { I, Adelino da Palma Carlos } \\
\text { 16/05 a 18/07/1974 }\end{array}$ & $\begin{array}{l}\text { intenção de renegociar os acordos comerciais de } \\
1972 \text { e manifestação dessa intenção }\end{array}$ \\
\hline $\begin{array}{l}\text { II, Vasco Gonçalves } \\
18 / 07 \text { a } 30 / 09 / 1974\end{array}$ & afastamento \\
\hline $\begin{array}{l}\text { III, Vasco Gonçalves } \\
\text { 30/09/1974 a 26/03/1975 }\end{array}$ & $\begin{array}{c}\text { propostas para modificar certas cláusulas do acordo } \\
\text { comercial de } 1972\end{array}$ \\
\hline $\begin{array}{l}\text { IV, Vasco Gonçalves } \\
26 / 03 \text { a } 08 / 08 / 1975\end{array}$ & afastamento e hesitação \\
\hline $\begin{array}{l}\text { V, Vasco Gonçalves } \\
08 / 08 \text { a } 19 / 09 / 1975\end{array}$ & rejeição de qualquer hipótese de associação à CEE \\
\hline $\begin{array}{l}\text { VI, Pinheiro de Azevedo } \\
19 / 09 / 1975 \text { a } 23 / 07 / 1976\end{array}$ & $\begin{array}{l}\text { renegociação do acordo comercial de 1972, tendente } \\
\text { à obtenção de ajudas e de formas de cooperação }\end{array}$ \\
\hline
\end{tabular}

Fonte: elaboração própria.

Mesmo perante este cenário adverso, no seio da CEE existia o entendimento de que não se deveria desamparar o país, pelo que a Comissão sugeriu, em Junho de 1975, uma ajuda económica e financeira de emergência, de modo a contribuir para o desenvolvimento económico do país e para mostrar aos portugueses que está disposta a ajudar um povo que está a

n. ${ }^{\circ}$ 563/1, "Communication à la Commission Transmise par Sir Christopher Soames, Vice-Président”, 13 Mai 1975.

${ }^{44}$ Entre 11 e 13 de Fevereiro 1975, vem acompanhado por Roland de Kergorlay, tendo-se encontrado com os ministros Emílio Rui Vilar, Mário Soares, José da Silva Lopes, e com o Primeiro-ministro Vasco Gonçalves e o Presidente da República, general Francisco Costa Gomes, além de representantes da Confederação da Indústria Portuguesa e da Intersindical. AHCE, BAC 250/1980 n. ${ }^{\circ} 372$.

Durante esta visita foram debatidos a situação económica do país e o Programa Económico e Social (ainda não era um plano). No final da reunião com Rui Vilar, este definiu as ambições portuguesas em relação à CEE: compreensão e confiança pelo caminho que Portugal está a trilhar, que ainda não está claramente definido; no âmbito social, melhoria da situação dos trabalhadores portugueses na CEE; apoio financeiro; e cooperação industrial e tecnológica. Soames respondeu que da parte da CEE Portugal terá ajuda no período de transição, mas para tal Portugal terá que dar indicações concretas nesse sentido. AHCE, BAC 25/1980 n. ${ }^{\circ} 1897 / 1$ - "Sir Christopher Soames' visit to Lisbon 12-13 February, 1975". 
caminhar no sentido da democracia ${ }^{45}$. Francisco Castro analisa a influência que tanto a CEE como os Estados Unidos da América (EUA) tiveram no período de transição para a democracia portuguesa, revelando duas posições distintas: para os EUA a presença de comunistas no governo não seria tolerada, mas não interviria, pelo que Portugal deveria servir de exemplo sobre os efeitos de uma governação comunista; para a CEE, deviam-se auxiliar os moderados, tendo em vista conduzir a evolução política rumo a uma democracia parlamentar ${ }^{46}$. Esta divergência de posições foi, aliás, também benéfica para a CEE, na medida em que "ao ser protelado o auxílio americano, a contribuição europeia tornava-se ainda mais decisiva, levando a CEE a granjear espaço político de afirmação por entre as superpotências"47.

No Conselho Europeu de Julho ${ }^{48}$, existe o entendimento de que a ajuda comunitária deve estar condicionada à evolução para a democracia pluralista, entendimento reafirmado em Outubro seguinte no Luxemburgo, ou seja, que o apoio da CEE dependia verdadeiramente da evolução da situação política portuguesa, o que nos remete para a relação entre democracia e ajuda financeira: a este respeito, a Comissão é peremptória quando menciona que "a ajuda de urgência deve enquadrar-se claramente numa perspectiva de consolidação de uma democracia pluralista em Portugal, sendo do

${ }^{45}$ Nesta comunicação é referido o "interesse natural em apoiar o esforço de Portugal no sentido da consolidação da ordem democrática e do progresso económico e social”, sendo recomendado que o apoio da CEE à democracia portuguesa seja concretizado "rapidamente e de forma espectacular", de modo a não desiludir os portugueses, e assim ter um maior efeito político. AHCE, BAC 250/1980 n. ${ }^{\circ} 378$, COM (75) 287 Final, "Communication de la Commission au Conseil relative aux mesures à prendre en faveur du Portugal”, 11 Juin 1975.

${ }^{46}$ CASTRO, Francisco - A CEE e o PREC. Penélope. 26 (2002) 123-157.

${ }^{47}$ VICENTE, Paulo Jorge Carvalho de Santos - Aqui sopram os ventos da Europa: os governos portugueses perante o federalismo e a integração europeia (1960-2002). Lisboa: FCSH, 2011, p. 264.

${ }^{48}$ Realizado entre 16 e 17, em Bruxelas, nas suas conclusões figura uma declaração sobre Portugal, na qual consta que a CEE está disposta a cooperar mais estreitamente no domínio económico e financeiro com Portugal, disposição essa que está condicionada a um Estado democrático pluralista. Historical Archives of the European Union (HAEU), BAC079/1982-229; AHCE, BAC 79/1982 n. ${ }^{\circ} 229$.

$\mathrm{O}$ assunto foi sendo acompanhado, e em reunião do Conselho de assuntos externos, a 15 de Setembro 1975, no que diz respeito às relações com Portugal, afirma-se que as perspectivas políticas parecem melhores para Portugal; pelo que, quando se confirmar um desenvolvimento positivo, poder-se-á concretizar a resolução de Julho do Conselho Europeu. HAEU, EN-000408. 
interesse da Comunidade apoiar Portugal para esse fim" acrescentando, porém, que, "se Portugal não prosseguir esse objectivo ou se tal se tornar inatingível, todos os argumentos apresentados em favor dessa ajuda perderão a sua validade" ${ }^{\text {"49 }}$. Precisamente sobre a relação existente entre democracia e integração europeia, Robert Fishman é da opinião que a CEE moldou, mas não fez as democracias do Sul da Europa, aquando da sua pretensão de se tornarem Estados-membros ${ }^{50}$, o que é corroborado pelas leituras acima, nas quais é demonstrado que a concessão de uma ajuda é condicionada à opção por um regime democrático.

A promessa de ajuda financeira, do lado da CEE, já havia sido proferida a 26 de Maio de 1975, depois de um Conselho de Ministros da CEE. No entanto, a 24 de Junho de 1975, os ministros dos Negócios Estrangeiros estavam reticentes quanto ao apoio económico a conceder a Portugal, devido à falta de estabilidade política, o que se traduziu, posteriormente, num veto do presidente francês, a 17 de Julho, a um empréstimo por parte da CEE. A Comissão Europeia, por seu lado, num memorando de 11 de Junho, corrobora essa pretensão, defendendo um auxílio económico para ajudar a democracia portuguesa ${ }^{51}$.

\footnotetext{
${ }^{49}$ AHCE, BAC 250/1980 n. ${ }^{\circ} 378$, COM (75) 287 Final.
}

Sobre os últimos desenvolvimentos acerca da condicionalidade democrática como pressuposto para a adesão, consultar: PRIDHAM, Geoffrey - Designing Democracy: EU Enlargement and Regime Change in Post-communist Europe. Houndmills: Palgrave Macmillan, 2005; MATTLI, Walter and PLÜMPER, Thomas - The Demand-side Politics of EU Enlargement: Democracy and the Application for EU Membership. Journal of European Public Policy. 9, Issue 4 (2002) 550-574.

${ }^{50}$ FISHMAN, Robert M. - Shaping, not Making, Democracy: The European Union and the Post-Authoritarian Political Transformations of Spain and Portugal. South European Society and Politics, volume 8, issue 1-2 (2003) 32.

${ }^{51}$ Durante a sessão de Estrasburgo do Parlamento Europeu (16 a 20 de Junho de 1975), o comissário europeu responsável pelas relações externas, Christopher Soames, apelou à CEE para concederem uma ajuda imediata e substancial a Portugal, ajuda essa que representaria "a expressão prática da Comissão no sentido de que a Comunidade deveria ajudar Portugal a progredir no sentido de uma democracia pluralista". Aliás, a Comissão desde o início que definiu os termos de uma ajuda: a instauração, consolidação de uma democracia e a defesa dos direitos humanos. Esta proposta era apresentada numa altura em que crescia o cepticismo entre os líderes europeus em relação aos últimos desenvolvimentos ocorridos em Portugal, e não estavam confiantes em relação ao efeito que uma ajuda poderia ter. Do lado da Comissão, esta proponha uma extensão dos acordos comerciais de 1972. HAEU, CPPE-000496. 
Entretanto, nas eleições para a Assembleia Constituinte, a 25 de Abril de 1975, o Partido Socialista obtém a vitória, o que indiciaria mudanças no cenário político, com um maior distanciamento em relação aos comunistas e a sua progressiva saída dos cargos governamentais.

Com a saída de Vasco Gonçalves e a formação do VI GP, de carácter pluripartidário, liderado pelo Almirante Pinheiro de Azevedo, nomeado pelo Presidente da República, general Costa Gomes, e, embora na tomada de posse se continuasse a advogar "a via do socialismo e da democracia pluralista para atingirmos a sociedade socialista" 52 , também se defendia a preferência que "através de um modelo democrático, aumentasse os seus graus de relação com as diversas Instituições Europeias" ${ }^{53}$, a CEE voltou a acreditar que Portugal seguiria a via da democracia pluralista, pelo que será já durante a vigência desse Governo, já sem uma marca comunista acentuada que, na reunião do Conselho, a 7 de Outubro de 1975, à qual assistia uma delegação portuguesa, na qual estavam os ministros Melo Antunes e Jorge Campinos, foi concedida uma ajuda financeira excepcional de emergência a Portugal ${ }^{54}$.

No início de 1976, quando começa a estabilização da democracia portuguesa, por um lado, e a renegociação dos acordos comerciais de 1972 por outro, ainda não se vislumbra a hipótese da adesão à CEE, o que não invalida que com essas negociações se comecem "a mexer as coisas e as vontades no sentido da aceitação da ideia da adesão" 55 .

\section{Conclusão}

Ao longo deste artigo evidenciamos a relação dos governos provisórios com a CEE numa perspectiva de adesão futura do país àquela organização,

${ }^{52}$ AZEVEDO, Pinheiro de - Entrevistas. Lisboa: Ministério da Comunicação Social, 1976, p. 37 (entrevista concedida ao O Jornal a 12-3-1976).

53 AZEVEDO, Pinheiro de - Entrevistas. cit., p. 63 (entrevista concedida ao jornal A Luta a 21-4-1976).

${ }^{54} \mathrm{O}$ Banco Europeu de Investimento disponibilizaria créditos no montante de 150 milhões de unidade de conta (à taxa de câmbio de 1975, representava cerca de cinco milhões de contos, aproximadamente 12,4 milhões de euros actualmente) com bonificação do juro de 3\% (=30 milhões de unidade de conta), paga pelo orçamento comunitário. Para mais detalhes sobre a ajuda excepcional de urgência, consultar: AHCE, BAC 48/1984 n. ${ }^{\circ}$ 563/1, 2, 3 e 4.

55 FERREIRA, Luiz Gonzaga - Portugal e as Comunidades Europeias - Do 25 de Abril ao Pedido de Adesão. Lisboa: Vega, 2001, p. 91. 
e qual o seu contributo para a aproximação e/ou afastamento em relação à mesma, durante um tempo de passagem em que se ensaiavam diferentes modelos de uma democracia à experiência.

Tentamos contribuir para um melhor entendimento do que foi a relação estabelecida entre os governos provisórios e a CEE durante a fase pré-constitucional do novo regime político português, numa altura em que a questão central residia no processo de descolonização, e todos os governos provisórios advogavam a via do socialismo e a instauração de uma democracia pluralista com vista a se alcançar uma verdadeira sociedade socialista, pelo que é neste enquadramento que devemos entender a questão da CEE e da integração europeia.

Durante dois anos apenas (entre Abril de 1974 e Abril de 1976) advogaram-se, sem grande debate, todavia, diversas opções de política externa e do lugar que o país deveria ocupar no mundo. Neste período, a CEE surge sempre como uma referência vaga nos programas dos governos provisórios e sempre numa vertente económica, pois não se afigurava conveniente estreitar relacionamentos políticos com potências capitalistas, como a Europa.

Num ambiente ideológico de esquerda, na prossecução de uma via socialista de Estado e de sociedade, a CEE era apenas uma entre outras opções potencialmente definidoras da identidade futura do país e do seu enquadramento geopolítico-económico, pelo que se compreende que durante a vigência dos governos provisórios a integração fosse "uma questão que só raramente era aflorada" ${ }^{56}$.

No cômputo geral, durante a vigência destes governos de transição, singraram três visões distintas e concorrentes: durante o I, II e III governos prevaleceu a estratégia euro-atlântica e pró-ocidental, defendida por Mário Soares; no IV e VI governos sobressaiu a opção "terceiro-mundista”, neutralista e não-alinhada de Melo Antunes; e, por fim, durante os II a V governos, prosseguiu-se uma direcção pró-soviética perfilhada por Vasco Gonçalves ${ }^{57}$.

${ }^{56}$ BRITO, José Maria Brandão de, ROLLO, M. F. e AMARAL, J. F. (ed.) - Portugal e a Europa - Testemunhos dos Protagonistas. Lisboa: Tinta da China, 2011, p. 202.

${ }^{57}$ MENDES, Pedro - A dimensão..., cit., p. 176. 
Por seu lado, a CEE não deixou de apoiar politicamente Portugal, condicionando, porém, a sua ajuda a nível financeiro à instauração do regime democrático. E foi apenas quando foram sanadas as principais tendências de um regime à esquerda que a CEE materializou esse apoio, em 1976, através da celebração de dois novos protocolos complementares aos acordos comerciais de 1972.

A História portuguesa conta com muitos tempos de passagem de um momento histórico para outro. Neste tempo, que conheceu seis governos provisórios, cuja durabilidade oscilou entre um e dez meses, qualquer definição ou elaboração mais precisa, concreta, estruturante, acerca do relacionamento, e seus moldes, do país com a CEE, seria caracterizada por falta de peso político e legitimidade, pelo que não estava, assim, destinado ser um governo provisório a aprofundar os contornos de um relacionamento já existente, mas com potencialidades para ser desenvolvido. 